\title{
The Response of Exchange Rate Pass-Through to the Macroeconomic Environment
}

\author{
Mark J. Holmes* \\ Department of Economics, Waikato University Management School, Private Bag 3105, Hamilton 3240, New Zealand
}

\begin{abstract}
This paper offers new insights into the nature of exchange rate pass through modelling in the context of a Markov regime-switching environment. Using New Zealand data, the results indicate that pass through to import prices resulting from fluctuations in the exchange rate or exporter costs can be characterised as regime-specific. Furthermore, there is evidence that the probability of switching between higher and lower pass through regimes is significantly influenced by inflation where stable rates of inflation increase the probability of remaining in a low pass through regime.
\end{abstract}

JEL Codes: E31, F41, F49.

Keywords: Exchange rate pass through, regime-switching, inflation.

\section{INTRODUCTION}

The extent of exchange rate pass-through (ERPT) from the nominal exchange rate to domestic prices is seen by many as being indicative of the extent of economic and financial interdependence. In terms of monetary policy, high ERPT might be viewed as consistent with low autonomy and high integration. On the other hand, low ERPT might signify high independence and the ability of the central authorities to implement inflation targeting ${ }^{1}$. Indeed, a decline in ERPT can have important macroeconomic implications. It might imply a change in the sensitivity to external shocks such as exchange rate fluctuations, but possibly also to shocks to commodities or other traded goods prices.

For a number of reasons, policymakers are interested in the measurement of EPRT. While exchange rate movements may have a sizeable impact on domestic inflation and on the general economic outlook, the transmission of monetary policy impulses to prices through the exchange rate channel is often regarded as faster than through the interest rate channel. A further consideration is that exchange rate changes can affect domestic inflation in various ways such as impacting directly on the domestic price of imported goods, feeding into the prices for final goods through raising the imported prices for raw materials, or impacting on the competitiveness of domestically produced goods. It can be argued that an appreciation of the exchange rate tends to reduce inflationary pressure, but a key question is by how much? Finally, ERPT to import prices affects expenditure switching in the domestic economy by changing the relative prices of imported and domestically produced goods. This raises the question of

*Address correspondence to this author at the Department of Economics, Waikato University Management School, Private Bag 3105, Hamilton 3240, New Zealand; E-mail: holmesmj@waikato.ac.nz

\footnotetext{
${ }^{1}$ Pass-through issues have also played a central role in debates over appropriate monetary policies and exchange rate regime optimality. See, for example, Smets and Wouters [1].
}

whether a decline in ERPT has weakened a channel through which current account imbalances can be corrected.

Several studies have already observed that the response of consumer prices to changes in nominal exchange rates has been both incomplete and varied over time. Sekine [2] and others have pointed to the decline in ERPT over the recent years where recent research suggests that ERPT declines in response to a credible low inflationary regime (see, inter alia, Bailliu and Fujii [3], Choudhri and Hakura [4], Holmes [5] and Taylor [6]). Indeed, many countries have experienced a sizeable decline in ERPT to domestic prices following improvements in the monetary policy framework. While Taylor [6] suggests that the establishment of a strong nominal anchor explains this, Sekine [2] suggests that the impact of the low and stable inflation environment on import prices is in fact weak.

This paper addresses the central research question of whether or not ERPT in New Zealand (NZ) has declined over the past twenty years where inflation has fallen considerably. In contrast to the existing ERPT literature, an alternative empirical approach is proposed where ERPT modelled within a Markov regime-switching framework giving rise to regimes of higher and lower ERPT. This enables an assessment of whether reductions in high and volatile rate of inflation increased the probability of the economy remaining in a regime characterised by relatively low ERPT. Most of the existing empirical research on this issue proceeds by splitting sample estimations or rolling regressions: these estimation techniques are based on the assumption that underlying parameters did not alter within the estimated sample periods, and thus they do not necessarily provide precise timing of parameter shifts. By employing a Markov-switching model, we offer new insight into ERPT because regime shifts in ERPT coefficients are embedded in the model in a way that enables the analysis of the inferred probability of regimeswitching and in particular, the influence of inflation volatility on the transition probabilities between regimes.

The paper is organised as follows. The following section discusses the relevant ERPT literature. The third section dis- 
cusses the application of the Markov regime-switching methodology in the context of a simple model of ERPT. Using this methodology, the following questions are addressed. First, is there evidence that ERPT in NZ has varied over the last twenty years or so? Second, if ERPT has varied, is there evidence that a varying ERPT is associated with a varying inflation rate? In addition to ERPT, this study also considers whether pass through with respect to exporter costs is subject to regime-switching. The fourth section describes the data and discusses the results. Evidence of complete ERPT for $\mathrm{NZ}$ is lacking throughout the study period. There is evidence of two ERPT regimes respectively characterised by low ERPT or some degree of balance between producer- and local currency pricing where inflation volatility affects the associated inferred probabilities of being in a particular regime. The final section concludes.

\section{RELEVANT LITERATURE}

The traditional ERPT literature is concerned with ERPT to import prices stressing the role of market power and price discrimination in international markets where exporters frequently "price to market" or pursue other forms of strategic pricing. Goldberg and Knetter [7] survey a literature which argues that import price pass-through is essentially determined by microeconomic factors such as demand elasticities and market structure. Much of this work builds almost exclusively on the concept of market segmentation where the discussion is set in an oligopolistic framework with imperfect competition and third degree price discrimination. Given segmented markets, the seminal papers of Dornbusch [8] and Krugman [9] spawned oligopolistic models based on the variations in mark-ups in response to exchange rate changes. Another line taken in the literature has its roots in Baldwin [10], Baldwin and Krugman [11] and Dixit [12]. This line of literature emphasises hysteretic effects arising from the sunk costs of entering a market that firms cannot recoup when they leave the market. A third direction in the literature concentrates on institutional settings such as the effects of nontariff barriers or the role of multinational corporations and intra-firm trade (see, for example, Menon [13-14]). For many, globalisation has led to increased cross-border production and a reduced exchange rate sensitivity of production costs.

While debate over the nature of pass-through concerns the prevalence of producer-currency versus local-currency pricing of imports, another interesting direction in the literature has recently argued that the extent of ERPT declines with the transition towards a credible low inflationary environment. Against a background of staggered price setting and monopolistic competition, Taylor [15] presents a dynamic general equilibrium open economy model where firms set prices for several periods in advance, but their prices respond more to price increases (due to exchange rate depreciation or other sources) if cost changes are perceived to be more persistent. Regimes with higher inflation appear to have more persistent costs and will therefore increase the extent of ERPT with firms experiencing greater pricing power. Referring to the low inflation episode of the 1990s, Taylor [15] argues that the persistence of inflation declined in the US. This is because firms expected changes in costs or prices to be less persistent therefore fewer exchange rate changes were passed through to domestic prices. Choudhri and Hakura [4] emphasise a similar channel to Taylor [15] where ERPT is reflected in the expected effects of monetary shocks on current and future costs, while Devereux and Yetman [16] argue that the frequency of price changes of importing firms declines with the degree of credibility attached to monetary policy. Finally, Devereux and Yetman [17] develop a theoretical framework to show how sticky prices represent a key determinant of exchange rate passthrough to consumer prices.

A number of empirical studies indicate a reduction in ERPT over time. For example, event studies by Cunningham and Haldane [18] of the 1992 depreciation and then 1996 appreciation in the UK, the 1992 depreciation in Sweden, and the 1999 depreciation in Brazil show a remarkably small pass-through of exchange rate changes to retail prices. Using a cross-sectional approach applied to various samples of countries, Choudhri and Hakura [4] and Devereux and Yetman [16] conduct a two-stage methodological approach. In the first stage, the ERPT coefficient is estimated for each country using time-series data. The second stage entails a regression of the ERPT coefficients against explanatory variables that include inflation. Using data for the Bretton Woods period, these studies find that inflation significantly explains the differences in the ERPT coefficients. Gagnon and Ihrig [19] use a similar two-stage approach for industrialised countries over the period 1971-2000. However, they subdivide their study period on the basis of inflationary experience and find that ERPT declined in the regime of low inflation. In most candidate countries, the high inflation environment of the early 1990s gradually changed into a single-digit inflation rate episode. Consequently, we might expect this development to influence the pass-through relationship. McCarthy [20] uses a VAR model to show a decline in exchange rate pass-through to consumer prices for all nine of the OECD countries examined in the period 1983-98 compared with the period 1976-82. According to these estimates, the pass-through declined by $50 \%$ or more in the US, UK, France, and Japan and by a smaller amount in Germany, Belgium, Netherlands, Sweden, and Switzerland. Finally, Bailliu and Fujii [3] employ a GMM panel data approach rather than cross sectional approach. Using data for eleven industrialised countries over the study period 1977-2001, they confirm the positive relationship between ERPT and inflation. Holmes [5] employs panel data cointegrating techniques to measure long run pass through and provides evidence of a decline in the EU since the 1970s. However, the early 1980s saw the extent of pass through actually increase despite the inception of the Exchange Rate Mechanism and reduction in average inflation rates as compared to a decade earlier. This suggests that it is not just lower inflation per se that will reduce the extent of pass through, but rather lower inflation combined with a credible regime of inflationary or monetary control.

\section{METHODOLOGY}

The micro-foundations of pricing behavior by exporters are a useful starting point for understanding the dynamics of ERPT into import prices. The import prices for any country $i$ $\left(P_{i t}^{m}\right)$ are a transformation of the export prices of that country's trading partners $\left(P_{i t}^{x}\right)$ using the exchange rate $\left(E_{i t}\right)$ 
measured as the domestic currency per unit of foreign currency:

$P_{i t}^{m}=E_{i t} P_{i t}^{x}$

Export prices, in turn, are a markup ( $\left.m k u p_{i t}^{x}\right)$ over exporter marginal costs $\left(m c_{i t}^{x}\right)$. Using lowercase letters to reflect logarithms, we may therefore rewrite equation (1) as

$p_{i t}^{m}=e_{i t}+m k u p_{i t}^{x}+m c_{i t}^{x}$

We may further allow markups to have both a countryspecific fixed effect and a component that is sensitive to macroeconomic conditions, expressed for simplicity as a function only of the exchange rate,

$m k u p_{i t}^{x}=\phi_{i}+\Phi_{i} e_{i t}$

Exporter marginal costs can be specified as rising with export market wages $\left(w_{i t}^{x}\right)$ and destination market demand conditions $\left(y_{i t}\right)$

$m c_{i t}^{x}=c_{0 i} y_{i t}+c_{1 i} w_{i t}^{x}$

Substituting equations (3) and (4) into (2) means that import prices can be written in general form as

$p_{i t}^{m}=\phi_{i}+\left(1+\Phi_{i}\right) e_{i t}+c_{0 i} y_{i t}+c_{1 i} w_{i t}^{x}$

This structure permits ERPT, represented by $a_{0}=\left(1+\Phi_{i}\right)$, to depend on the structure of competition in the economy. This is consistent with the large literature on explaining cross-sectional differences on ERPT, which has been summarized by Dornbusch [8] and Marston [21], among others, and supported empirically by Knetter [22] and Yang [23]. This structure also has a direct analogy in the discussion of producer- versus local-currency pricing. If $\Phi_{i}=0$, producer-currency pricing takes place. If $\Phi_{i}=-1$, local-currency pricing takes place where exporters fully absorb the fluctuations in exchange rates in their own markups.

We can capture the arguments of equation (5) through a log linear regression specification similar to that tested throughout the ERPT literature:

$p_{i t}^{m}=\alpha_{i}+a_{0} e_{i t}+b_{0} w_{i t}+c_{0} y_{i t}+\varepsilon_{i t}$

where $w_{i t}$ is redefined as a primary "control" variable representing exporter costs relevant to country $i$, and $y_{i t}$ is a vector of other controls, including the real GDP of the destination market. To incorporate lags into the short-run ERPT relationship, equation (6) can be rewritten as

$p_{i t}^{m}=\alpha+\sum_{j=0}^{4} a_{j} e_{i t-j}+\sum_{j=0}^{4} b_{j} w_{i t-j}+\sum_{j=0}^{4} c_{j} y_{i t-j}+\sum_{j=1}^{4} d_{j} p_{i t-j}^{m}+\varepsilon_{i t}$

While this paper focuses on modelling and estimating ERPT within a regime-switching context, regime-switching in exporter cost pass through (ECPT) is also allowed for. Suppose a discrete random variable $S_{t}$ takes two possible values $S_{t}=[0,1]$ and serves as an indicator for the state of the economy at time $t$. The expected change in import prices, conditional on the value of $S_{t}$, is given as:

$$
\begin{gathered}
E\left(p_{t}^{m} \mid S_{t}\right)=\left[\left(1-S_{t}\right) \alpha_{0}+S_{t} \alpha_{1}\right]+\left(1-S_{t}\right) \sum_{j=0}^{4} a_{0, j} e_{t-j}+S_{t} \sum_{j=0}^{4} a_{1, j} e_{t-j}+ \\
\left(1-S_{t}\right) \sum_{j=0}^{4} b_{0, j} w_{t-j}+S_{t} \sum_{j=0}^{4} b_{1, j} w_{t-j}+\sum_{j=0}^{4} c_{j} y_{t-j}+\sum_{j=1}^{4} d_{j} p_{t-j}^{m}+\varepsilon_{t}
\end{gathered}
$$

where $\varepsilon_{t} \sim$ i.i.d.N $\left(0, \sigma_{\varepsilon}^{2}\left(S_{t}\right)\right)$ and the regime-specific coefficients on the exchange rate and exporter costs are respectively denoted as $a_{0, j}, a_{1, j}, b_{0, j}, b_{1, j}$. Following Hamilton [24], the unobserved indicator variable, $S_{t}$, evolves according to a firstorder Markov-switching process: $\operatorname{Pr}\left[S_{t}=0 \mid S_{t-1}=0\right]=p_{00}$, $\operatorname{Pr}\left[S_{t}=1 \mid S_{t-1}=0\right]=\left(1-p_{00}\right), \operatorname{Pr}\left[S_{t}=1 \mid S_{t-1}=1\right]=p_{11}$ $\operatorname{Pr}\left[S_{t}=0 \mid S_{t-1}=1\right]=\left(1-p_{11}\right)$ where $p_{00}$ and $p_{11}$ are the fixed transition probabilities of being in Regime 0 or 1 respectively. This model can be denoted as the Fixed Transition Probabilities (FTP) Model. This model allows ERPT to be regime-specific characterised by differing elasticities. Extending the fixed two-state Markov-switching chain to allow for the possibility of time-varying transition probabilities enables us to specify:

$$
\begin{aligned}
& \operatorname{Pr}\left[S_{t}=0 \mid S_{t-1}=0, \Omega_{t-1}, \Omega_{t-2}, \cdots\right]=p_{00}=\Psi\left(\varsigma_{0}+\sum_{j=1}^{m} \vartheta_{j} \Omega_{t-j}\right) \\
& \operatorname{Pr}\left[S_{t}=1 \mid S_{t-1}=1, \Omega_{t-1}, \Omega_{t-2}, \cdots\right]=p_{11}=\Psi\left(\varsigma_{1}+\sum_{i=1}^{n} \kappa_{j} \Omega_{t-j}\right)
\end{aligned}
$$

where $\Psi()$ is the cumulative normal distribution function ensuring that the transition probabilities lie in the open interval $(0,1)$ and $\Omega$ denotes exchange rate volatility. This gives rise to Time-varying Transition Probabilities (TVP) Model where exchange rate volatility affects the probability of being in a particular regime.

In contrast to this approach, Sekine [2] employs a Kalman filter-based time-varying parameter procedure to show that ERPT has declined in the cases of the US, Japan, Germany, France, Italy and the UK over the period 1974-2004. This is followed by an auxiliary regression of ERPT coefficients on a number of variables that includes inflation volatility. In common with earlier ERPT studies, the procedure used by Sakine is two-step which raises issues associated with efficiency and the use of generated regressors. Rather than embed structural break type regime shifts in the pass through coefficients, Sekine acknowledges that this technique is only able to consider gradual changes in the pass through coefficients over time.

\section{DATA AND RESULTS}

This study employs quarterly data for the study period 1987Q2-2007Q2. Data for the nominal and real effective exchange rates are taken from the OECD database ${ }^{2}$, while

\footnotetext{
2 Alternative measures of the nominal and real exchange rates from the Bank of International Settlements were obtained for NZ. These measures exhibited a very high correlation coefficient with the OECD rates of the
} 
import price and real GDP data are taken from the Statistics New Zealand database. Following Campa and Goldberg [25], exporter costs relevant to NZ, $w_{t}$, is proxied by taking the log real effective exchange rate and subtracting both the log nominal effective exchange rate and the log domestic consumer price index. This provides a measure of tradingpartner costs (over all partners of NZ) with each partner weighted by its importance in NZ trade. Finally, inflation volatility is based on a four quarter moving standard deviation of the change in the log domestic consumer price index.

Having started with a maximum of four lags, the inclusion of contemporaneous values for $e, w$ and $y$ in equation (8) and one lagged value of $\Omega$ in equation (9) was found to be acceptable using various model selection procedures. These procedures were based on a general-to-specific approach starting with the four lags then applying sequential lag restriction tests until the lag restrictions were rejected by the data. Further to this, the results reported were found to be robust to a range of alternative starting values in the iterative maximisation process. The estimates of the log likelihood values associated with both the single-regime OLS and FTP models are reported in Table $\mathbf{1}$. The application of the nonstandard LR-test proposed by Davies [26] produces a statistic of 16.054 that leads to the rejection at $5 \%$ significance of the single-regime OLS model in favour of the regimeswitching FTP Model. Given the evidence in favour of regime-switching ERPT, this study considers whether the transition probabilities are constant or time-varying (as represented by equation (9)). Table 1 reports that the preferred model involving time-varying transition probabilities offers a significant improvement in log likelihood function. This is underlined with a LR statistic of 5.388 that rejects the null of fixed transition probabilities at the $6.8 \%$ significance level. $^{3}$

Table 1. Tests for Regime-Switching

\begin{tabular}{|c|c|c|c|c|c|}
\hline LL: OLS & LL: FTP & LL: TVP & $\mathbf{L R}_{\mathbf{1}}$ & $\mathbf{L R}_{\mathbf{2}}$ & $\mathbf{L R}_{\mathbf{3}}$ \\
\hline \hline 203.027 & 211.054 & 213.748 & $\begin{array}{c}16.054 \\
(0.025)\end{array}$ & $\begin{array}{c}5.388 \\
(0.068)\end{array}$ & $\begin{array}{c}21.442 \\
(0.011)\end{array}$ \\
\hline
\end{tabular}

LL: log likelihood values derived from estimation of the OLS, FTP and TVP models: $L_{1}$ : LR statistic for testing the null of no regime-switching against the alternative of regime-switching with fixed transition probabilities. The $\mathrm{LR}_{1}$ statistic is distributed as $\chi^{2}(7)$ on the null. $\mathrm{LR}_{2}$ : LR statistic for testing the null of regime-switching with fixed transition probabilities against the alternative of regime-switching with varying transition probabilities. The $\mathrm{LR}_{2}$ statistic is distributed as $\chi^{2}(2)$ on the null. $\mathrm{LR}_{3}$ : LR statistic for testing the null of no regime-switching against the alternative of regimeswitching with varying transition probabilities. The $\mathrm{LR}_{3}$ statistic is distributed as $\chi^{2}(9)$ on the null. Figures reported in the brackets are Davies [26] upper bound pvalues.

Table 2 reports the estimated TVP Model. Part A indicates that the estimated short-run ERPT coefficients $a_{0,0}$

order 0.99 and using these alternative measures made no qualitative difference to the main findings reported and discussed here.

${ }^{3}$ Further testing indicates that the TVP Model is preferred to the OLS single-regime model at the $1.1 \%$ significance level with an LR statistic of 21.442 which is distributed as $\chi^{2}(9)$ on the null. In addition to this, support for the TVP model was provided through the rejection of the null $\vartheta_{1}=\kappa_{1}=0$ with $\chi^{2}(2)=10.019$. and $a_{1,0}$ are both positive and significantly different from zero. With coefficients of 0.230 and 0.468 , it would appear that ERPT is lower in Regime 0 than in Regime 1. This is confirmed with the strong rejection of the null $a_{0,0}=a_{1,0}$ shown in Part C. In Regime 0, ERPT is based on an emphasis towards local currency pricing rather than producer pricing. While this value compares with the single regime shortrun elasticity of 0.22 computed for NZ by Campa and Goldberg [25], Regime 1 is characterised by a much more balanced combination of local currency and producer pricing. In the case of ECPT, matters are different. The estimates for $b_{0,0}$ and $b_{1,0}$ indicate regime-specific pass through coefficients of 0.007 and 0.097 , however only the latter is significantly different from zero. As in the case of ERPT, rejection of the restriction $b_{0,0}=b_{1,0}$ confirms that Regime 0 is the lower pass through regime. Furthermore, the results here indicate that $a_{0,0}>b_{0,0}$ and $a_{1,0}>b_{1,0}$ which implies that

Table 2. Estimation of the TVP Model

Part A. Regime-Variant Coefficients

\begin{tabular}{|c|c|c|c|}
\hline \multicolumn{2}{|c|}{ Regime 0 } & \multicolumn{2}{|c|}{ Regime 1 } \\
\hline \hline$\alpha_{0}$ & $\begin{array}{c}4.039^{* * *} \\
(0.126)\end{array}$ & $\alpha_{1}$ & $\begin{array}{c}4.761^{* * *} \\
(0.214)\end{array}$ \\
\hline$a_{0,0}$ & $\begin{array}{c}0.230^{* * *} \\
(0.020)\end{array}$ & $a_{1,0}$ & $\begin{array}{c}0.468^{* * *} \\
(0.032)\end{array}$ \\
\hline$b_{0,0}$ & 0.007 & $b_{1,0}$ & $\begin{array}{c}0.097^{* * *} \\
(0.022)\end{array}$ \\
\hline \multirow{2}{*}{$\sigma_{0}$} & $\begin{array}{c}(0.017) \\
(0.00008 * * *\end{array}$ & $\sigma_{1}$ & $\begin{array}{c}0.0004 * * * \\
(0.0001)\end{array}$ \\
\hline \multirow{2}{*}{$\varsigma_{0}$} & $\begin{array}{c}(82.169 * * * \\
(83.606)\end{array}$ & $\varsigma_{1}$ & $\begin{array}{c}3.981 * * \\
(1.664)\end{array}$ \\
\hline$\vartheta_{1}$ & $-1185.763 * * *$ & $\kappa_{1}$ & $\begin{array}{c}-4.994 \\
(6.088)\end{array}$ \\
\hline
\end{tabular}

Part B. Regime-Invariant Coefficients

\begin{tabular}{|c|c|}
\hline$c_{0}$ & $0.063^{* * *}$ \\
& $(0.012)$ \\
\hline \multirow{2}{*}{$d_{1}$} & 0.466 \\
& $(0.024)$ \\
\hline
\end{tabular}

Part C. Tests of Restrictions on Regime-Variant Coefficients

\begin{tabular}{|c|c|}
\hline$a_{0,0}=a_{1,0}$ & $63.790^{* * *}$ \\
\hline$b_{0,0}=b_{1,0}$ & $13.398^{* * *}$ \\
\hline$\vartheta_{1}=\kappa_{1}$ & $17.426^{* * *}$ \\
\hline$\sigma_{0}=\sigma_{1}$ & $10.168^{* * *}$ \\
\hline
\end{tabular}

Standard errors are reported in parentheses. $* * *, * *$ and $* *$ : rejection of the null at the 1,5 and $10 \%$ significance levels respectively. 
ERPT is greater than ECPT whichever regime is being considered. Exporters to NZ are more likely to pass on nominal exchange rate fluctuations than changes in their costs. Finally, Part B shows that the coefficient on the regimeinvariant control variable $y_{t}$ - is both positive and significant suggesting there is an inelastic relationship between domestic import prices and GDP growth, while the estimate $d_{1}=0.466$ is consistent with dynamic stability in the model.

With regard to the transition probabilities of switching between regimes, $\vartheta_{1}<0$ indicates that an increase (decrease) in inflation volatility is associated with a decrease (increase) in the probability of remaining in the lower ERPT Regime 0 . This is in turn has a negative impact on the expected duration of Regime 0. Fig. (1) graphs the inferred probabilities of remaining in Regime $0\left(p_{00}\right)$ against inflation volatility. Following the announcement of inflation targeting for NZ in 1989, the inferred probability actually declined during the very early 1990s. However, it then increased and remained high during the mid to late 1990s. Fig. (1) shows that this period is associated with a general decrease in inflation volatility. The period of 1999 onwards has seen a decline in the probability of remaining in the low ERPT regime though with a notable positive spike in 2003. This period has been characterised by a slight increase in inflation volatility than was the case in the 1990s. Finally, the estimates of these inferred probabilities can be used to compute a weighted fitted value for $p_{t}^{m}$ using the two regime-specific equations. Using this data, Fig. (2) provides a visual indication that the model is able to effectively track the behavior of $p_{t}^{m}$ over the study period.

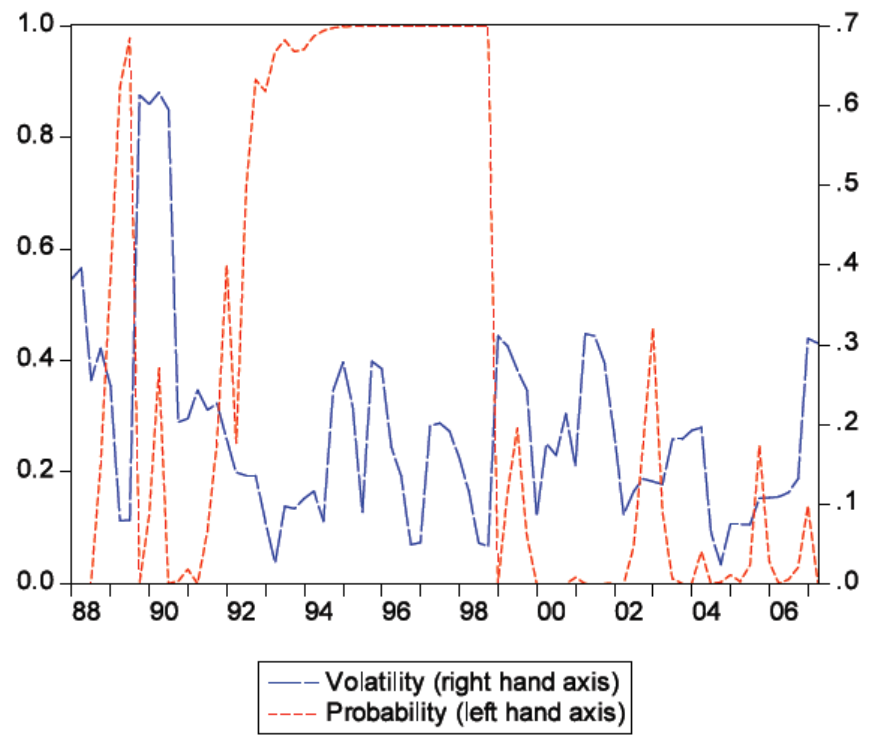

Fig. (1). Inferred probability of regime 0 and inflation volatility.

The results reported here imply that economic interdependence between NZ and its trading partners has increased during the current decade where both ERPT and ECPT are higher in the 2000s than before. However, with values that are slightly below 0.5 , there is still some degree of insulation from external shocks that may assist the Reserve Bank of NZ in implementing inflation targeting. More generally, there are potential implications for the achievement of inflation targets and monetary policy. Depending on the prevailing regime, a $10 \%$ appreciation of the nominal exchange rate will reduce import prices by $2.3-4.7 \%$. In terms of reducing inflationary pressure, the effectiveness of a given appreciation is enhanced in a volatile inflationary regime. It is likely that the sizeable fluctuations in the nominal exchange rate during the current decade have exerted larger effects on domestic prices than was the case in the 1990s. This suggests that monetary policy may have a harder task to stabilize domestic inflation in the presence of large negative exchange rate shocks than was previously the case. Since the effects of exchange rate fluctuations on inflation and output may be less sizeable if inflation volatility decreases, monetary policy in NZ should still take into account these fluctuations so as to anchor inflation expectations (and to stabilise output). A further issue to consider here is the impact of exchange rate realignment on the large current account deficit currently experienced by NZ. Import prices are showing more responsiveness to exchange rate depreciation, but this is still on the basis of an inelastic relationship.

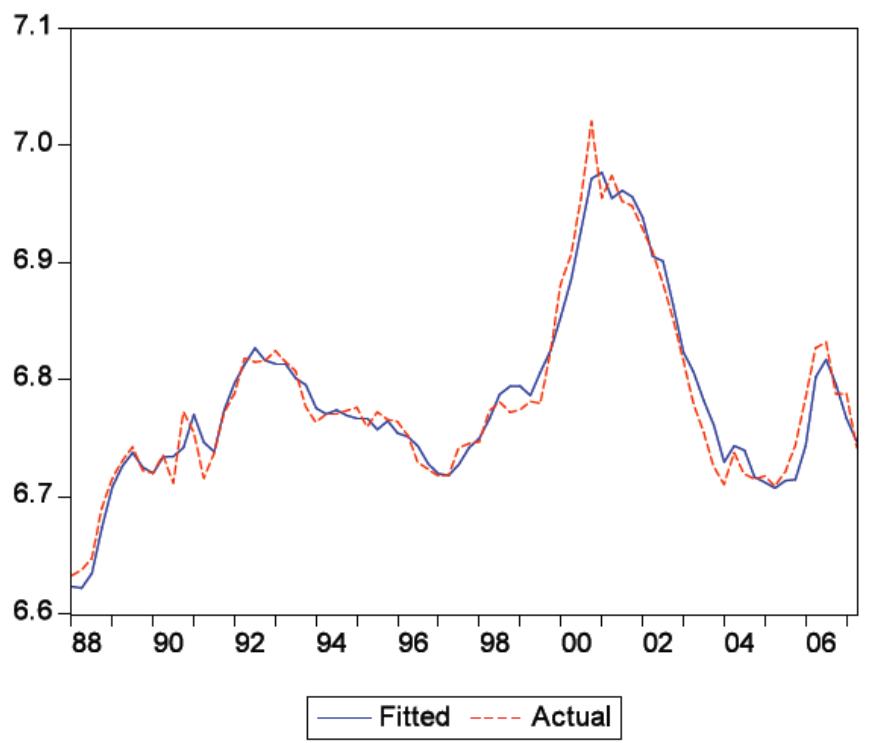

Fig. (2). Actual and fitted values for log import prices.

\section{CONCLUDING COMMENTS}

The employment of Markov regime-switching techniques offers a new perspective on exchange rate pass through to import prices. By endogenising the transition probabilities associated with regime-switching, the results for New Zealand provided in this study suggest that pass through can be viewed as subject to regime-switching between higher and lower rates of pass through where inflation volatility influences the probability of switching between these regimes. Further confirmation of this is provided by pass through with respect to exporter costs. These findings have important implications for the conduct of monetary policy in the context of inflation targeting insofar as greater inflation volatility is likely to be associated with increased pass through. Against a background of a weakening (strengthening) exchange rate, the central bank is likely to have a harder (easier) task of achieving an inflation target if inflation is volatile. The analysis so far has been conducted at an aggregated level. Future research might provide additional insights through an 
examination of regime-switching pass through at a more disaggregated sectoral level.

\section{ACKNOWLEDGEMENTS}

I am grateful for the helpful and insightful comments provided by two anonymous referees in addition to Alexander Jung and others at the 2008 Western Economics Association International (WEAI) Conference held in Hawaii. The usual disclaimer applies.

\section{REFERENCES}

[1] Smets F, Wouters R. Openness, imperfect exchange rate passthrough and monetary Policy. J Monet Econ 2002; 49: 947-82.

[2] Sekine T. Time-varying exchange rate pass-through: experiences of some industrial countries. Bank of International Settlements Working Paper 2006; No. 202.

[3] Bailliu J, Fujii E. Exchange rate pass through and the inflation environment in industrialised countries: an empirical investigation. Bank of Canada Working Paper 2004; No. 2004-21.

[4] Choudhri E, Hakura D. Exchange rate pass through to domestic prices: does the inflationary environment matter? IMF Working Paper 2001; No. WP/01/094.

[5] Holmes MJ. Is a low inflation environment associated with reduced exchange rate pass through? Finnish Econ Pap 2006; 19: 58-68.

[6] Taylor J. The monetary transmission mechanism and the evaluation of monetary policy rules. In: Loayza N, Schmidt-Hebbel K, Eds. Monetary Policy: Rules and Transmission Mechanisms. Central Bank of Chile Santiago 2002.

[7] Goldberg PK, Knetter M. Goods prices and exchange rates: what have we learned? J Econ Lit 1997; 35: 1243-72.

[8] Dornbusch R. Exchange rates and prices. Amer Econ Rev 1987; 77: 93-106.

[9] Krugman P. Pricing to market when the exchange rate changes. In: Arndt SW, Richardson JD, Ed. Real-financial linkages among open Economies. MIT Press: Cambridge Mass 1987.

[10] Baldwin R. Hysteresis in import prices: the beachhead effect. Am Econ Rev 1988; 78: 773-85.
[11] Baldwin R, Krugman P. Persistent trade effects of large exchange rate shocks. Quart J Econ 1989; 104: 635-54.

[12] Dixit A. Hysteresis, import penetration, and exchange rate passthrough. Quart J Econ 1989; 104: 205-28.

[13] Menon J. Exchange rate pass-through. J Econ Stud 1995; 9: 197231.

[14] Menon J. The degree and determinants of exchange rate passthrough: market structure, non-tariff barriers and multinational corporations. Econ J 1996; 106: 434-44.

[15] Taylor J. Low inflation, pass-through, and the pricing power of firms. Europ Econ Rev 2000; 44: 1389-408.

[16] Devereux MB, Yetman J. Price-setting and exchange rate passthrough: theory and evidence. in Price adjustment and monetary policy. Proceedings of a conference held at the Bank of Canada 2003; Ottawa; pp. 347-71.

[17] Devereux MB, Yetman J. Price adjustment and exchange rate passthrough. Mimeograph 2005.

[18] Cunningham A, Haldane A. The monetary transmission mechanism in the United Kingdom: pass through and policy rules. In Monetary policy: rules and transmission mechanisms. Edited by Loayza N, Scmidt-Hebbel K. Banco Central de Chile, Santiago 1999.

[19] Gagnon J, Ihrig J. Monetary policy and exchange rate pass-through. Board of Governors of the Federal Reserve System International Finance Discussion Paper 2002; No. 704.

[20] McCarthy J. Pass-through of exchange rates and import prices to domestic inflation in some industrialized economies. Federal Reserve Bank of New York 2000.

[21] Marston R. Pricing to market in Japanese manufacturing. J Int Econ 1990; 29: 217-36.

[22] Knetter M. International comparisons of pricing to market behavior. Amer Econ Rev 1993; 83: 473-86.

[23] Yang J. Exchange rate pass-through into US. manufacturing industries, Rev Econ Statist 1997; 79: 95-104.

[24] Hamilton JD. A new approach to the economic analysis of nonstationary time series and the business cycle. Econometrica 1989; 57: 357-84.

[25] Campa JM, Goldberg LS. Exchange rate pass through into import prices. Rev Econ Statist 2005; 87: 679-90.

[26] Davies RB. Hypothesis testing when a nuisance parameter is present only under the alternative. Biometrika 1987; 74: 33-43.

(C) Mark J. Holmes; Licensee Bentham Open.

This is an open access article licensed under the terms of the Creative Commons Attribution Non-Commercial License (http://creativecommons.org/licenses/by$\mathrm{nc} / 3.0 /$ ) which permits unrestricted, non-commercial use, distribution and reproduction in any medium, provided the work is properly cited. 